Salas Acosta, Luz Marina.

Profesora adscrita al Departamento de Dibujo. Universidad de Sevilla.

Sáez Pradas, Fernando.

Investigador adscrito al Departamento de Dibujo. Universidad de Sevilla.

\title{
Archivo y coleccionismo: fotografía española en el s. XX.
}

\author{
TIPO DE TRABAJO \\ Comunicación virtual. \\ PALABRAS CLAVE \\ Fotografía, coleccionismo, patrimonio, archivo. \\ KEY WORDS \\ Photography, art collecting, heritage, archive.
}

RESUMEN

El grupo HUM-950 (COPA) COntemporaneidad y PAtrimonio ha promovido el desarrollo de las Jornadas de divulgación científicas "Fotografía: COntemporaneidad y PAtrimonio", financiadas por la Universidad de Sevilla, y cuyo objetivo general ha sido iniciar una de las líneas argumentales del grupo de investigación, la de unir contemporaneidad y patrimonio.

Dadas las circunstancias socio-políticas en nuestro país, la fotografía no tuvo el reconocimiento merecido en las instituciones ni colecciones de nuestro país. La fotografía en España tuvo menos oportunidades que el resto de países de nuestro entorno, por ello el coleccionismo en esta disciplina es un fenómeno relativamente nuevo existiendo un número muy reducido de colecciones y coleccionistas dedicados específicamente a la materia fotográfica.

Los fundamentos de esta compleja situación tienen su origen en diversos ámbitos: por un lado dependía de la formación de los propios artistas y teóricos, y por el otro con la programación que las instituciones, públicas o privadas, hacían sobre la fotografía.

La búsqueda de reconocimiento social o el mero interés económico forman parte de las razones que llevan a crear una colección. Pero hay otro tipo de coleccionismo que se acerca a la necesidad de formar parte del colectivo cultural uniendo dos figuras importantes: la del coleccionista y la del mecenas.

Hablar del coleccionismo fotográfico en el arte contemporáneo es acercarnos a un fenómeno relativamente reciente. Las colecciones privadas, que hoy en algunos casos consideramos como modelos, se gestaron a partir de los años 80 , aunque los museos franceses y americanos ya a partir de los años 50 tomaron la iniciativa de coleccionar fotografía con un carácter patrimonial, lo que les llevaba a coleccionar casi exclusivamente autores de su propio país.

\section{ABSTRACT}

The group named HUM-950 (COPA) "COntemporaneidad y PAtrimonio" -Contemporaneity and Legacy- has promoted the scientific dissemination sessions "Fotografía: COntemporaneidad y PAtrimonio" -Photography: Contemporaneity and Legacy-, funded by the University of Seville and for the purpose of starting one of the group's research topics: connecting contemporaneity and legacy. 
Due to the social and economic situation in our country, photography was never adknowledged by the Spanish establishment or collections. Photography in Spain had less opportunities than it had in countries in our area, which is the reason why collection is a fairly new discipline and there is such a small number of collections and collectors specifically involved in the subject of photography.

The foundations for this complex situation are based on several fields: on the one hand it depended on artists and theorists' training and on the other hand it depended on the photography schedule planned by the public or private establishment.

The search for social appreciation or even just the economic concern are part of the reasons which lead to the origination of a collection. But there is a different way of collecting which approaches the need for being part of the cultural collective. This is achieved by joining two important characters: the collector and the patron.

Talking about photography collecting in contemporary art makes us think about a relatively recent trend. Private collections, which are sometimes thought of as models, have been devised since the 1980s despite the fact that French and American museums led the way in collecting art on a patrimonial base since the 1950s. This took them to collect works by nearly exclusively their fellow countrymen.

\section{INTRODUCCIÓN}

El grupo HUM-950 (COPA) COntemporaneidad y Patrimonio, inicia una de las líneas argumentales de trabajo del Grupo de investigación: La fotografía, a través de las Jornadas titulada "Fotografía: COntemporaneidad y PAtrimonio". El estudio fue posible gracias a la concesión de las ayudas para Actividades de Divulgación Científicas (III.2) de la convocatoria del V Plan propio de Investigación. Universidad de Sevilla. El ciclo de Conferencias tuvo lugar en los pasados días 4 y 5 de marzo de 2015 en el Centro de Iniciativas Culturales (CICUS) de la Universidad de Sevilla, con quien ha colaborado para la exposición de las mismas.

Asimismo, se planteaba el acercamiento del análisis de esta disciplina a un colectivo interesado en las prácticas contemporáneas entre los que obviamente se encontraban los estudiantes de las facultades de Bellas Artes y de Historia del Arte. A ellos se ha añadido en las conferencias un grupo de profesionales que participó activamente en el desarrollo de las mismas.

\section{OBJETIVOS}

Las jornadas ofrecieron a través de un ciclo de conferencias relacionadas con el coleccionismo y la fotografía las siguientes actividades:

- Conferencia - taller de los artistas participantes

- Entrevista con los artistas

- Transcripción de las conferencias y de las entrevistas

- Grabación audio.

La finalidad de dichas actividades (audios, conferencias, entrevistas,...) no fue otro que poner al alcance de investigadores del ámbito de las artes, profesionales o cualquier otra persona interesada en estos temas, un material inédito de figuras destacadas dentro de los diferentes campos tratados. Todo este material se puede encontrar de manera libre en la página web del grupo de investigación: https://grupo.us.es/copa/

\section{DESARROLLO}

\section{- 10 Jornada. "Fotografía: COntemporaneidad y PAtrimonio".}

Daniel Canogar (Madrid, 1964) artista visual trabaja con fotografía, video e instalación.

Sus trabajos se han expuesto en el Museo de Arte Contemporáneo Reina Sofia, Madrid; bitforms Gallery, Nueva York; Galería Filomena Soares, Lisboa; Galerie Guy Bärtschi, Ginebra; Mimmo Scognamiglio Arte contemporanea, Milán; Centro de Arte Santa Mónica, Barcelona; Museo Alejandro Otero, Caracas; Wexner Center for the Arts, Ohio; Offenes Kulturhaus Center for Contemporary Art, Linz; Museo Kunstsammlung Nordrhein Westfallen, Dusseldorf; Museo Hamburger Banhof, Berlín; Borusan Contemporary 
Museum de Estambul; Museo de Historia Natural, Nueva York; Museo Andy Warhol, Pittsburgh y Mattress Factory Museum, Pittsburgh.

Ha publicado "Ciudades Efímeras: Exposiciones Universales, Espectáculo y Tecnología", Julio Ollero Editor, Madrid, 1992; "Ingrávidos", Fundación Telefónica, Madrid, 2003; y diversos ensayos sobre la arquitectura de la imagen, la fotografía contemporánea y el arte de los nuevos medios.

El conferenciante Daniel Canogar nos acerca en su intervención hacia numerosas reflexiones sobre la naturaleza del arte, tratando aspectos tan importantes como: la originalidad artística, el problema de autoría, la reproducción de las obras artísticas, el artista como coleccionista, el valor mercantil de su propia producción y el arte en la sociedad de masas.

Daniel nos habla también de aspectos más técnicos de su trabajo haciendo un recorrido por la obra y el sentir del propio artista. Finalmente nos habla de las vicisitudes del artista ante su nuevo papel como empresario y de sus acciones para poder mantener la empresa y a sus trabajadores, tocando aspectos puramente mercantilistas.

En segundo lugar Carlos Gollonet, editor y comisario de exposiciones de fotografía, ofreció una interesantísima conferencia. Conservador Jefe de Fotografía de la Fundación Mapfre. Desde comienzos de los años 90 ha comisariado más de veinte exposiciones de fotografía: Helen Levitt, Richard Misrach, Hiroshi Sugimoto, Lee Friedlander, Garry Winogrand, Harry Callahan y Nicholas Nixon, entre otros. Ha publicado numerosos artículos en libros y revistas especializadas, invitado como conferenciante y miembro de diversos jurados de fotografía (PHotoEspaña, FotoPres, Cartier-Bresson Award, Foto Levallois, etc.). En 2010 se le concedió el Premio Entrefotos 2010.

Carlos comienzó hablando del coleccionismo fotográfico español y cómo la Fundación Mapfre es consciente del lugar que tiene la fotografía en las colecciones artísticas, nos cuenta que a través de la oferta del programa de actividades de la Fundación nos dan la oportunidad de conocer a fotógrafos, críticos, ensayistas, comisarios,... Protagonistas todos ellos de la renovación historiográfica que cada vez más genera un mayor interés del público por conocer y disfrutar la fotografía.

Prosiguió hablándonos de la colección de la Fundación y se centró en el siglo XIX y XX, en como la fotografía pasa de herramienta de registro y clasificación de la realidad a medio de experimentación y desarrollo estético-artístico donde la sensibilidad y la imaginación ocupa un lugar importante.

Entre otras fuentes fotográficas, mostró imágenes del proyecto de las hermanas Brown, obra del fotógrafo Nichael Nixon, proyecto de larga duración que comenzó en 1975 y continua en la actualidad.

Finalizó explicando el sentido del coleccionismo y su función social y cultural.

- 2o Jornada. "Fotografía: COntemporaneidad y PAtrimonio".

Abrió la segunda sesión el experto en gestión y archivo fotográfico Miguel García Cárceles, de la Diputación de Valencia y Asistente Técnico en las colecciones de fotografía. Coordinador del equipo de gestión documental en PROYECTO DFOTO, UNIVERSIDAD POLITECNICA DE VALENCIA. Destaca su labor como Investigador en el proyecto Europeo DAGUERREOBASE en el equipo de investigación del lemfc. UPV.

El conferenciante ha centrado su intervención en la parte más técnica y descriptiva del archivo fotográfico. Miguel nos habla de la falta de visibilidad del patrimonio fotográfico español, siendo la causa por la que el grupo de investigación al cual pertenece decide crear una línea de investigación orientada a aumentar la difusión de este patrimonio.

Miguel nos explica con todo detalle el proyecto dFoto: directorio de colecciones digitales y la manera en que nos ofrece la información sobre los fondos y colecciones de fotografías que se encuentran por el territorio español.

Habló también de los resultados obtenidos en esta primera etapa: recogida de datos y difusión. Información obtenida de los centros dependientes del Ministerio de Educación, Cultura y Deportes, y los Archivos Municipales, habiendo ya completado los Archivos de las Diputaciones Provinciales, los Archivos Históricos Provinciales y una muestra representativa de centros y coleccionistas privadas, volcadas en la base de datos http://www.dfoto.info/.

Finalmente puntualizó la importación del proceso de actualización, puesto que el trabajo de identificación y catalogación de materiales fotográficos en muchas instituciones está todavía en proceso, y la tendencia creciente de las instituciones por aumentar nuevos fondos y colecciones fotográficas. También nos habló de los problemas que tienen con el almacenamiento y mantenimiento en la que muchas ocasiones se encuentran las obras. 
El segundo ponente fue Pep Benlloch. Profesor Titular de fotografía en la Facultad de Bellas Artes de Valencia. Universitat Politècnica de València. Director del "Máster en fotografía" de la Universitat Politècnica de València. Codirector del programa de doctorado "Fotografía y nuevos medios audiovisuales: De lo analógico a lo digital". Director del laboratorio para el estudio de los materiales fotográficos contemporáneos. Director de la Galería Visor desde su fundación en 1982 hasta 2009 y comisario de numerosas exposiciones.

Esta conferencia resultó tan brillante como reveladora. No fue un enfoque meramente descriptivo sino analítico del panorama actual de la fotografía española. Pep nos habla de la fotografía como docente, como artista, como galerista incluso como coleccionista.

Pep Benlloch comenzó una intervención inteligente y bien construida afirmando que se ha banalizado la fotografía, convirtiéndose a veces en un producto más de consumo de masas. Nos cuenta que la relación del artista del siglo pasado con las imágenes era muy diferente, se aproximaba más a un diálogo unidireccional entre el espectador y la imagen captada casi intuitivamente. Destacó el poder innovador de la fotografía de estos años afirmando que ésta es mucho más moderna y muchas de las fotografías actuales.

Prosiguió haciendo un recorrido de autores nacionales que reflejan los diversos momentos de la fotografía española: pictorialismo tardío, la Guerra Civil, la renovación de la década de los 50 y los 60, el auge del fotoperiodismo, el ensayo fotográfico y la fotografía de ficción en los 70 y los 80, dándonos a conocer nombres que, si bien está reconocido en el mundo de la fotografía no es tan conocido por el público general, como son: Pere Catalá-Pic, Francesc Catalá Roca, Agustín Centeller, Koldo Chamorro, Pepe Florido, Ramón Mastas, Nicolás Muller, Jorge Rueda,...

Finalizó hablando de su experiencia en este campo como galerista y coleccionista, reivindicando así la fotografía en España.

\section{CONSLUSIONES}

Las jornadas finalizaron con una gran afluencia de público entre los que destacamos estudiantes y profesionales del sector de las artes plásticas y visuales. La transferencia de conocimiento y el debate que se generó tras las sesiones ha puesto en valor la necesidad de hablar sobre el coleccionismo en el ámbito de la fotografía, uno de los grandes desconocidos en nuestro país. Gracias a la aceptación que ha tenido, ya se ha planteado su continuidad con unas segundas jornadas para el curso académico 2015/16, en las que seguir profundizando en los conceptos propuestos.

Para finalizar señalaremos, con un especial énfasis, la importancia que ha tenido para la sostenibilidad de la producción fotográfica, el coleccionismo por parte de instituciones privadas como públicas y particulares. Esto ha hecho que se active una actividad ausente en nuestro país tras la dictadura franquista y que si estaba teniendo lugar en países como Francia, Inglaterra o Estados Unidos. 